\title{
Article \\ Mechanical Performance of Fiber Reinforced Cement Composites Including Fully-Recycled Plastic Fibers
}

\author{
Cesare Signorini ${ }^{1, *,+} \mathbb{D}$ and Valentina Volpini ${ }^{2,+}$ \\ 1 Research Centre "CRICT", Department of Engineering "Enzo Ferrari", Via Vivarelli 10, 41125 Modena, Italy \\ 2 Research Centre "En\&Tech", Department of Sciences and Methods for Engineering, P.le Europa 1, \\ 42124 Reggio Emilia, Italy; valentina.volpini@unimore.it \\ * Correspondence: cesare.signorini@unimore.it; Tel.: +39-(0)59-2056337 \\ + These authors contributed equally to this work.
}

Citation: Signorini, C.; Volpini, V. Mechanical Performance of Fiber Reinforced Cement Composites Including Fully-Recycled Plastic Fibers. Fibers 2021, 9, 16. https://doi. org/10.3390/fib9030016

Academic Editor: Aliakbar Gholampour

Received: 07 January 2021

Accepted: 15 February 2021

Published: 1 March 2021

Publisher's Note: MDPI stays neutral with regard to jurisdictional clai$\mathrm{ms}$ in published maps and institutional affiliations.

Copyright: (C) 2021 by the authors. Licensee MDPI, Basel, Switzerland. This article is an open access article distributed under the terms and conditions of the Creative Commons Attribution (CC BY) license (https:// creativecommons.org/licenses/by/ $4.0 /)$.

\begin{abstract}
The use of virgin and recycled plastic macro fibers as reinforcing elements in construction materials has recently gained increasing attention from researchers. Specifically, recycled fibers have become more attractive owing to their large-scale availability, negligible cost, and low environmental footprint. In this work, we investigate the benefits related to the use of fully-recycled synthetic fibers as dispersed reinforcement in Fiber Reinforced Cement Composites (FRCCs). In light of the reference performance of FRCCs including virgin polypropylene (PP) fibers only, the mechanical response of composites reinforced with polyolefin filaments treated with a sol-gel silica coating and polyethylene terephthalate (PET)/polyethylene (PE) cylindrical draw-wire fibers is here assessed through three-point bending tests. Remarkably, recycled polyolefins lead to a notable enhancement in terms of peak strength and post-crack energy dissipation capability. This improvement is ascribed to both the flattened shape of fibers and the surface coating, which turns out to be very effective at strengthening the fiber-to-matrix bond. On the other hand, PET/PE fibrous reinforcement generally leads to a lower toughness, if compared to the virgin fibers. However, no reduction in terms of peak stress is evidenced. Balancing the significance of mechanical performance and environmental sustainability in the framework of a circular economy approach, both fully-recycled fibers at hand can be regarded as promising candidates for innovative structural applications.
\end{abstract}

Keywords: Fiber Reinforced Cement Composite (FRCC); recycled polyolefin; recycled polyethylene terephthalate; silica coating; coated fiber; polypropylene fiber; Fiber Reinforced Concrete (FRC)

\section{Introduction}

Fiber Reinforced Cement Composites (FRCCs) represent well-established structural technologies finding wide application in several fields of civil engineering, e.g., industrial floorings, earthquake-resistant structures, and tunnel linings. Some pioneering works guide the contemporary research to broaden the fields of application of FRCC, and Fiber Reinforced Concrete (FRC) in particular, in the attempt of pursuing high-performance composite systems. Di Prisco et al. [1] investigated the possible use of FRC in precast plates for lightweight and performing roofing elements, while an intensive study on the mechanical behavior of full-scale precast structural beams was conducted by Vandewalle [2]. As also established in other fundamental contributions [3,4], the addition of fibers in plain concrete improves the resistance to crack formation and propagation, due to the bridging mechanism implemented by the fibrous reinforcement. Moreover, the use of short dispersed fibers assures a meaningful reduction of shrinkage cracking, a more favorable crack distribution, and hence an enhanced durability of the structural elements [5-7].

Recently, synthetic fibers made of polymeric materials have been proposed as a promising and relatively inexpensive reinforcement in FRCCs, representing alternatives to asbestos, glass, and steel fibers. The latter, in particular, are traditionally considered as the most effective reinforcement strategy to improve the bending capacity of structural 
elements, given the wide experience inherited in the field of reinforced concrete [8]. Recent studies have also focused on the reduction of their environmental footprint, by retrieving steel fibers from recycled tires [9-11] or industrial waste [12]. However, plastic fibers have attracted the interest of the scientific community owing to their superior durability (i.e., absence of corrosion), light weight, and thermal properties, with specific reference to the fostering of anti-spalling attitude [13].

Among synthetic materials, both polyethylene terephthalate (PET) and polyolefins, especially polypropylene (PP) and polyethylene (PE), are regarded as interesting candidates for manufacturing recycled fibers, owing to their good recycling capabilities, significant mechanical properties, and large-scale availability. Their extreme versatility, in fact, has put them among the most popular plastics in use worldwide, as declared by the leading European trade association PlasticEurope. According to PlasticEurope-The Facts 2020 report [14], European demand for PP, low density PE, and PET in 2019 represents 19.4\%, $17.9 \%$, and $7.9 \%$ of the total production, respectively, with packaging accounting for nearly $40 \%$. The wide difference between usage time (few minutes) and time for natural decaying (several centuries) generates unavoidable environmental concerns, encouraging the scientific community to look for innovative solutions involving recycled plastic waste.

In more detail, PET is a thermoplastic polymer belonging to polyesters, whose physical and mechanical characteristics highly depend on the manufacturing process. It is mainly employed for manufacturing beverage containers, whose production has been increasing steadily and continuously since the late 1970s [14]. Recently, the potential benefits related to the addition of recycled PET fibers in cement composites has been widely investigated. Ochi et al. [15] experimentally assessed the effects of draw-wired PET indented fibers included in concrete mixtures up to a $1.5 \%$ volumetric dosage. Remarkably, a pronounced hardening effect is detected after matrix cracking, followed by an increase in both bending strength and absorbed energy. Similarly, Fraternali et al. [16] found a significant improvement of both mechanical and thermal properties with respect to plain concrete. Marthong and Sarma [17] investigated a different solution, by adopting as reinforcement recycled PET platelets from beverage containers. A benefit in bending peak load is observed, according to the findings by Foti $[18,19]$, who tested PET fibers with different shapes. Besides, Pelisser et al. [20] observed an increase in both flexural toughness and impact resistance. However, the last contribution also highlights the crucial problem of degradation of PET in cement, which leads to a loss of long-term mechanical response of the composite. This issue is extremely controversial, as Ochi et al. [15] pointed out that no detrimental effects were observed in their experimental tests. For this reason, further studies and well-defined test practices are required. The interesting research by Won et al. [21] went right in this direction, thoroughly assessing the durability of FRCCs including PET fibers under five different chemical conditions, by confirming the aggressiveness of alkaline and sulphuric acid environments on recycled fibers.

Alongside PET, polyolefins are thermoplastic polymers which result from the polymerization of olefins, including propylene and ethylene [22]. Remarkable ductility and good impact resistance characterizing PE along with light weight and high tensile strength of PP make polyolefins particularly suitable for manufacturing consumer goods, including food packaging, pipes, and covers, as well as automotive and aerospace elements. Several studies have been conducted on FRCCs and FRCs reinforced with recycled polyolefin fibers, assessing their good performance reached at an almost negligible cost [23-25]. Among them, a recent contribution by Signorini et al. [26] investigated the mechanical and environmental performance of fully-recycled blended PE/PP filaments, obtained from disposed artificial turf pitches for sport facilities. Positively, an appreciable improvement in the post-crack energy dissipation capability was observed. However, the measured ultimate flexural strength significantly reduces, mainly due to the weak adhesion of fibers to the surrounding inorganic matrix. As is well known, the lack of hydrophilicity and compatibility of polyolefins, ascribable to their non-polar nature [27], and polyesters, which also show a marked hydrophobic attitudes [28,29], currently represents a major drawback, which limits 
the use of synthetic fibers in FRCs for structural applications [30]. The inability to transfer the load from the matrix to the fibers, in fact, jeopardizes the mechanical performance of the composite, which is generally subject to delamination failure [31-33]. To address this problem, several surface treatments of fibers have been proposed in the literature, involving among others oxyfluorination [34], chemical attack [35], cold plasma [36], and silica coating $[37,38]$. The last, while being a relatively simple technique, turns out to be particularly suitable at improving the interface bonding between synthetic fibers and cement binder (see, e.g., [7,39]).

In the present work, we assess the mechanical response of a pre-mixed cement mortar reinforced with homogeneously dispersed fully-recycled fibers, namely PET/PE cylindricalshaped draw-wire filaments and blended PE/PP flattened fibers (see [26]), the latter coated with a rapid acid-catalysed sol-gel silica treatment. We performed three-point bending tests, by comparing the results with reference performance of FRCCs including virgin PP fibers only. We observe that two main parameters affect the effectiveness of fibrous reinforcement, namely the shape (flattened platelets vs cylindrical fibers) and, primarily, the superficial treatment. The coating, in fact, greatly improves the energy absorption of the composite during the cracked stage, which is mainly driven by the interphase adhesion at the matrix-to-fiber transition zone.

\section{Materials and Methods}

\subsection{Raw Materials}

Two different fully-recycled synthetic fibers, henceforth referred to as RP (Recycled Polymers) and AT-S (Artificial Turf - Silica), were tested as reinforcement phase in a single commercially available pre-mixed ordinary Portland cement (OPC) mortar, whose properties of interest are listed in Table 1, according to the manufacturer datasheet [40].

RP fibers, illustrated in Figures 1a and 2a, consist of a blend of PET/PE (designed in accordance with PlasticFiber Srl, Bologna, Italy). This polymeric mixture was retrieved from processing disposed food packaging, then milled, and eventually extruded as cylindricalshaped draw-wired fibers $1 \mathrm{~cm}$ long (diameter $0.70 \mathrm{~mm}$ ).

AT-S are PE/PP blended fibers, directly obtained from processing disposed artificial turf carpets (Sabbie di Parma Srl, Parma, Italy) for sport facilities (for a complete characterization, please refer to [26]). As illustrated in Figure 1b, fibers are flattened, with a surface morphology characterized by wide wrinkles across the transverse cross-section (optical magnification in Figure $2 \mathrm{~b}$ ) and length ranging from 1 to $4 \mathrm{~cm}$. Here, AT-S fibers were treated with a rapid acid-catalysed sol-gel silica coating, whose effectiveness is assessed through comparison with the performance of untreated fibers, henceforth referred to as AT (Artificial Turf).

Table 1. Mechanical and physical properties of the OPC mortar [40].

\begin{tabular}{ccc}
\hline Characteristic [Regulation] & Unit & Value \\
\hline Max. grain size & $\mu \mathrm{m}$ & 500 \\
Permeability to water [EN 1504-2] & $\mathrm{m}$ & 1.10 \\
Water absorption [EN 1062-3] & $\mathrm{kg} / \mathrm{m}^{2} \mathrm{~h}^{-0.5}$ & 0.08 \\
Flexural strength [EN 196-1] & $\mathrm{MPa}$ & 4.0 \\
Compressive strength [EN 12190] & $\mathrm{MPa}$ & 27.0 \\
Elastic modulus [EN 13412] & $\mathrm{GPa}$ & 15.2 \\
Adhesion to concrete [EN 1542] & $\mathrm{MPa}$ & 1.1 \\
Water/cement ratio & - & 0.43 \\
\hline
\end{tabular}

A quick acid-catalysed silica treatment was realized by following the process illustrated in [33] and hereafter briefly summarized. A silicon alkoxide precursor was suitably hydrolyzed by mixing with water. Then, a polycondensation reaction led to the formation of a colloidal suspension of solid particles in liquid, named polymeric sol [37]. Specifically, the materials here employed are tetraethyl orthosilicate $\mathrm{SiC}_{8}-\mathrm{H}_{20} \mathrm{O}_{4}(98 \%$ TEOS, 
Sigma-Aldrich Inc.) and Isopropyl alcohol $\mathrm{C}_{3} \mathrm{H}_{8} \mathrm{O}$ (99.7\%, Sigma-Aldrich Inc.). By means of a magnetic stirrer, these high-purity reactants were mixed together in stoichiometric ratio, for $15 \mathrm{~min}$ at a temperature of $50^{\circ} \mathrm{C}$. Then, nitric acid $\mathrm{HNO}_{3}$, acting as catalyst, and deionized water were mixed together and eventually added to the solution, which was continuously stirred for an additional $2 \mathrm{~h}$, maintaining a temperature of $50{ }^{\circ} \mathrm{C}$. At this point, $\mathrm{PE} / \mathrm{PP}$ fibers were immersed in the silica sol-gel for a few minutes and finally dried at room temperature.

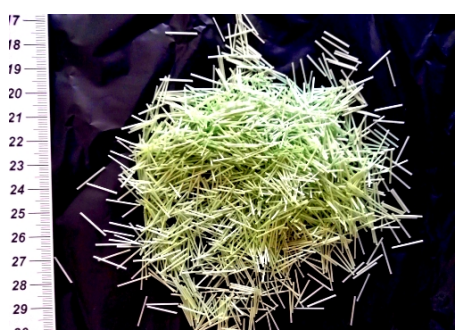

(a) Recycled PET/PE fibers from

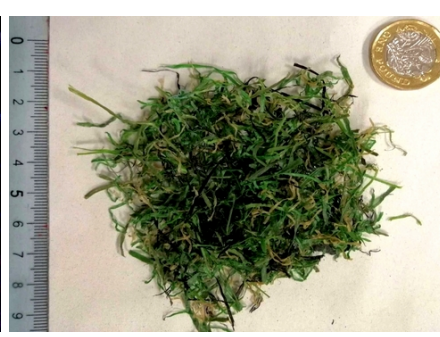

(b) Recycled PE/PP fibers from (c) artificial turf

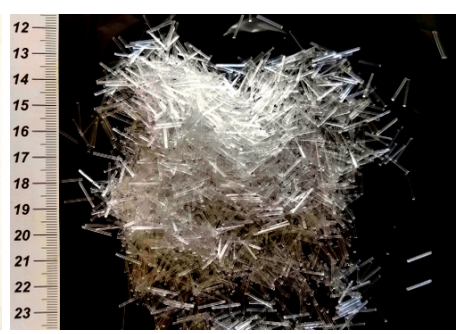

(c) Virgin PP draw-wired fibers (reference) packaging

Figure 1. Recycled and virgin fibers in hand for the investigation.

The behavior of both RP and AT-S fibers is discussed in light of the reference performance of virgin PP fibers, named PP, illustrated in Figures 1c and 2c. Relevant geometrical and physical properties of RP, AT-S, and PP fibers are summarized in Table 2.

Table 2. Geometrical and physical properties of fibers.

\begin{tabular}{cccc}
\hline Fiber & Characteristic & Unit & Value \\
\hline \multirow{2}{*}{ RP } & Diameter & $\mathrm{mm}$ & 0.80 \\
& Length & $\mathrm{cm}$ & 1 \\
& Density & $\mathrm{kg} \mathrm{m}^{-3}$ & 1350 \\
\hline \multirow{3}{*}{ AT/AT-S } & Thickness & $\mathrm{mm}$ & $\leq 0.10$ \\
& Width & $\mathrm{mm}$ & $0.5 \div 1.5$ \\
& Length & $\mathrm{cm}$ & $1-4$ \\
& Density & $\mathrm{kg} \mathrm{m}^{-3}$ & 985 \\
\hline \multirow{2}{*}{$\mathrm{PP}$} & Diameter & $\mathrm{mm}^{2}$ & 0.90 \\
& Length & $\mathrm{cm}^{-3}$ & 1 \\
& Density & $\mathrm{kg} \mathrm{m}^{-3}$ & 946 \\
\hline
\end{tabular}

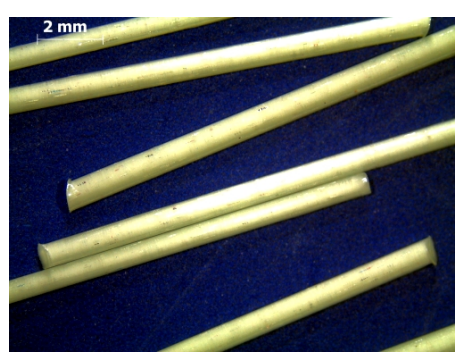

(a) Recycled PET/PE fibers from packaging

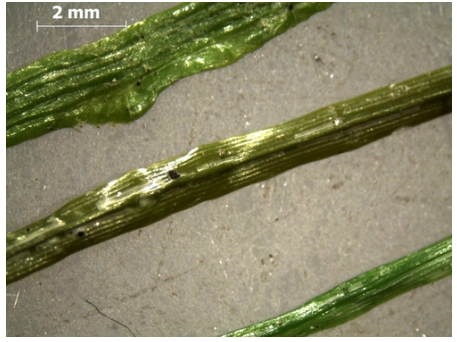

(b) Recycled PE/PP fibers from (c) artificial turf

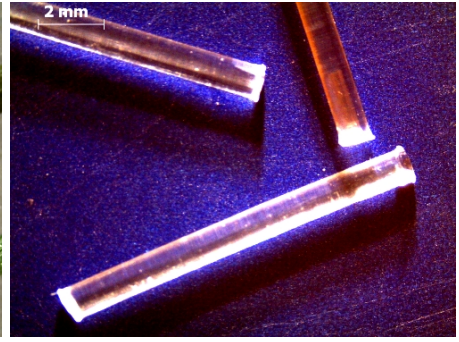

(c) Virgin PP draw-wired fibers (reference)

Figure 2. Stereomicroscopy images of the fibers in hand for the investigation.

\subsection{Specimens Manufacturing}

With reference to UNI EN 1015-11 [41] (testing methods for cement and lime hardened mortars for structural purposes), we manufactured four sets of $40 \mathrm{~mm} \times 40 \mathrm{~mm} \times 160 \mathrm{~mm}$ prismatic beams, each of which was reinforced by the addition of a $3 \%$ vol. percentage of 
RP, AT-S, AT, and PP fibers, respectively. First, fibers were homogeneously incorporated and dispersed in the solid fraction of the OPC mortar (binder and aggregates), by means of a low speed mechanical stirrer. Then, water was added to the mix, and the fresh mortar was further stirred, cast into accurately lubricated formworks, and eventually jolted to foster the surfacing of air bubbles. The specimens were then moist-cured within the molds for 2 days, demolded, and tightly wrapped in polypropylene foils $(100 \% \mathrm{RH})$ for further 5 days. Finally, curing was accomplished in a Peltier-based climatic chamber $\left(20^{\circ} \mathrm{C}\right.$ and $65 \pm 5 \% \mathrm{RH}$ ) for 21 days [42] [Table 1]), until complete hardening.

\subsection{Surface Characterization Methods}

To assess the effectiveness of the silica surface treatment, Fourier transform infrared (FT-IR) spectrometry was performed on both AT and AT-S fibers, by means of a FTIR Vertex 70 (Bruker Optik GmbH, Ettlingen, Germany). This technique allows us to accurately characterize the chemical composition on the surface of coated AT-S fibers, to be compared with the reference uncoated AT filaments. The spectrometry was accomplished under Attenuated Total Reflection (ATR) mode, and the IR spectrum was obtained for wavenumbers ranging $4000-600 \mathrm{~cm}^{-1}$.

With the aim of revealing the presence of silica particles on AT-S filaments and qualitatively evaluating the surface roughness, the surface of fibers was examined in detail through the observation under an environmental scanning electron microscope (E-SEM) (Quanta FEI company, Eindhoven, The Netherlands), equipped with the backscatteredelectron (BSE) detector, recommended for the easy identification of elements with different atomic number.

\subsection{Mechanical Tests}

The mechanical characterization of the four sets of FRCCs was performed through three-Point Bending (3PB) tests. We employed an Instron 5567 electromechanical Universal Testing Machine (UTM), equipped with a $30 \mathrm{kN}$ load cell and a two-point support, with anvils placed $10 \mathrm{~cm}$ apart. We conducted the tests by controlling the displacement rate of the upper cross-head, whose prescribed value is $1 \mathrm{~mm} / \mathrm{min}$ (tests were performed by referring to [42], which prescribes an applied load speed of 50-100 N/s. However, according to our previous experience [43], we performed displacement-controlled mechanical tests, by adopting a comparable displacement speed of $1 \mathrm{~mm} / \mathrm{min}$ ). The mechanical testing program is reported in Table 3.

Table 3. Experimental program.

\begin{tabular}{|c|c|c|c|}
\hline Set & Description & Fibers Volume Fraction & Specimens \\
\hline $\mathrm{PP}$ & $\begin{array}{l}\text { FRCC beams with virgin PP } \\
\text { cylindrical fibers (reference) }\end{array}$ & \multirow{4}{*}{$3 \%$} & \multirow{4}{*}{5} \\
\hline $\mathrm{RP}$ & $\begin{array}{l}\text { FRCC beams with fully-recycled } \\
\text { cylindrical PET/PE fibers }\end{array}$ & & \\
\hline $\mathrm{AT}$ & $\begin{array}{l}\text { FRCC beams with fully-recycled } \\
\text { PE/PP flattened fibers }\end{array}$ & & \\
\hline AT-S & $\begin{array}{l}\text { FRCC beams with fully-recycled } \\
\text { silica-coated PE/PP flattened fibers }\end{array}$ & & \\
\hline
\end{tabular}

We discuss the performance of FRCCs in terms of mean strength curves, peak load, $F_{\mathrm{p}}$, flexural modulus, $E_{\mathrm{f}}$, and mechanical energy dissipated at failure, $W$. More specifically, $E_{\mathrm{f}}$ is a secant modulus, evaluated as the slope of the straight line intersecting the stress-strain $(\sigma-\varepsilon)$ curve at two fixed points, according to the following relation:

$$
E_{\mathrm{f}}=\frac{0.9 \sigma_{\mathrm{p}}-0.6 \sigma_{\mathrm{p}}}{\left.\varepsilon\right|_{0.9 \sigma_{\mathrm{p}}}-\left.\varepsilon\right|_{0.6 \sigma_{\mathrm{p}}}} .
$$


In Equation (1), $\sigma_{\mathrm{p}}$ is the peak stress reached by the specimen, whereas the notation $\left.\varepsilon\right|_{n \sigma_{\mathrm{p}}}$ is adopted to indicate the strain attained at $n \sigma_{\mathrm{p}}$. On the other hand, $W$ expresses the area under the $\sigma-\varepsilon$ curves, here evaluated as

$$
W=\int_{0}^{\varepsilon_{f}} \sigma(\varepsilon) d \varepsilon
$$

in which $\varepsilon_{\mathrm{f}}$ indicates the strain corresponding to $0.1 \sigma_{\mathrm{p}}$, reached in the post-peak branch.

\section{Results and Discussion}

\subsection{FT-IR and E-SEM Analyses}

To assess the efficiency of the silica coating, we first conducted FT-IR analyses on both treated AT-S and uncoated reference AT fibers. The comparison between the observed surface spectra is reported in Figure 3.

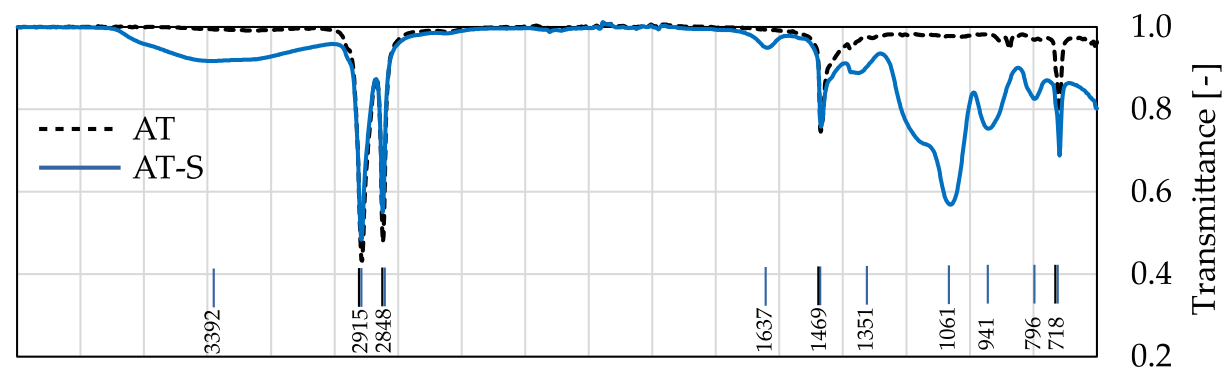

$\begin{array}{llllllllllllllllll}4.0 & 3.8 & 3.6 & 3.4 & 3.2 & 3.0 & 2.8 & 2.6 & 2.4 & 2.2 & 2.0 & 1.8 & 1.6 & 1.4 & 1.2 & 1.0 & 0.8 & 0.6\end{array}$

Wavenumber $\left[\cdot 10^{3} \mathrm{~cm}^{-1}\right]$

Figure 3. FT-IR spectra for uncoated (AT) and silica coated (AT-S) fibers.

By focusing on AT spectrum (black dashed line), two main peaks at 2915 and $2848 \mathrm{~cm}^{-1}$ are observed, revealing the typical $\mathrm{C}-\mathrm{H}$ stretching in $\mathrm{CH}_{2}$ groups. In addition, two further absorbance peaks at 1469 and $718 \mathrm{~cm}^{-1}$, ascribable to the symmetric $\mathrm{C}-\mathrm{H}$ bending and rocking in $\mathrm{CH}_{3}$, respectively, evidence that $\mathrm{PE}$ is the main component of the blend. The last observation is consistent with the results of DSC analyses carried out by Signorini et al. [26], who, despite detecting the occurrence of two main endothermic reactions (ascribed to PE and PP melting), qualitatively suggested the predominant presence of PE within the blend, given the very low enthalpy of transition associated to the PP melting stage. In particular, because of the linear relationship between the decrease of the PP melting peak and the amount of PP in the blend (see [44] [Figure 4]), we estimate a PP content ranging 20-30\%, as a consequence of the decrease of the PP melting peak around $2.1 \%$, with respect to the expected value. We remark that FT-IR analysis here performed is crucial to characterize the fully-recycled mixture, whose PE/PP contents may be subject to significant variations.

By recalling the spectrum of pure silica (see, e.g., [45] [Figure 4]), analysis of AT-S spectrum (blue solid line) leads to the following fundamental observations:

- A smooth and pronounced absorbance peak appears around $3392 \mathrm{~cm}^{-1}$, due to the strong oxidation provided by the sol-gel treatment. The addition of hydrophilic functional $\mathrm{O}-\mathrm{H}$ groups as a consequence of the coating deposition, in fact, promotes the activation of the surface. This effect was also highlighted by Ahsani and Yegani [30], who studied silica nanocomposites within a different context.

- A remarkable absorbance peak detected at $1061 \mathrm{~cm}^{-1}$ gives evidence of the asymmetric stretching in $\mathrm{Si}-\mathrm{O}-\mathrm{Si}$ groups, owing to the presence of silicon dioxide molecules (see, e.g., [46]).

- A small peak at $1637 \mathrm{~cm}^{-1}$ evidences the presence of moisture, due to the diffused absorption of water molecules (hygroscopic attitude of silica) [47].

Therefore, the adhesion of the coating to the polymeric fibers turns out to be very successful, as further confirmed by the environmental SEM analysis illustrated in the following. 
Surface of uncoated AT fibers (Figure 4a) appears smooth and plain, except for the presence of deep wrinkles along the longitudinal direction (black stretched area). Here, bright small traces reveal the presence of environmental fine dust, which inevitably settles on fiber surface during handling and storage. On the other hand, wide light areas standing out against the dark polymeric substrate are observed in Figure $4 \mathrm{~b}$, highlighting the presence of a consistent silica layer deposited on the surface of treated AT-S fibers. These high-brightness areas are a consequence of the high atomic number of silica, which can scatter a large amount of electrons with respect to the organic fibers (mainly $\mathrm{C}-\mathrm{H}$ and $\mathrm{O}$ atoms, having low atomic numbers).

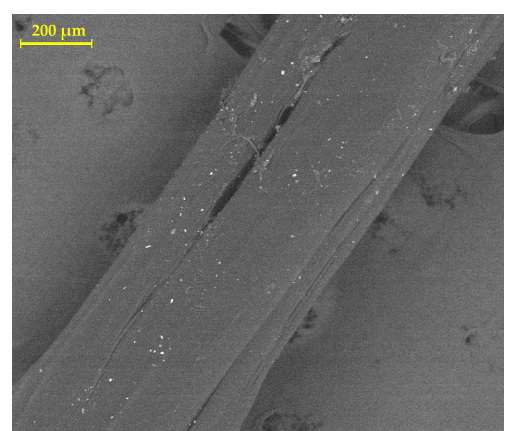

(a) AT

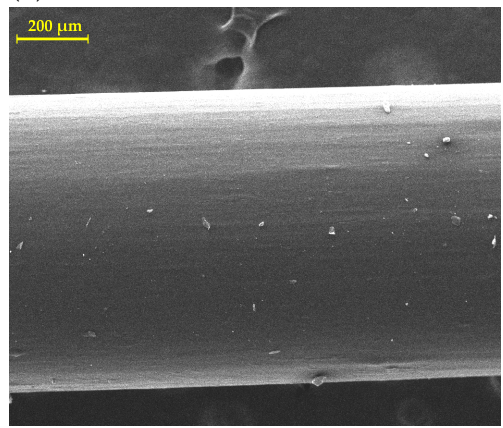

(c) RP

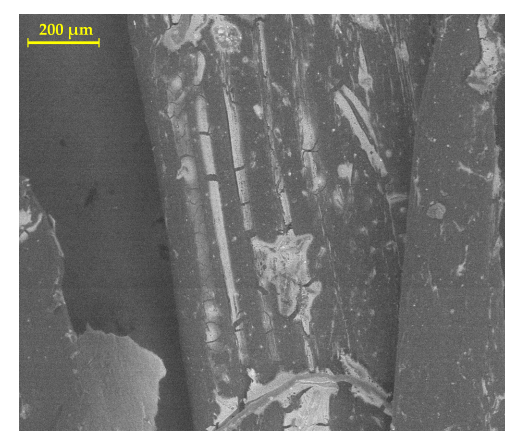

(b) AT-S

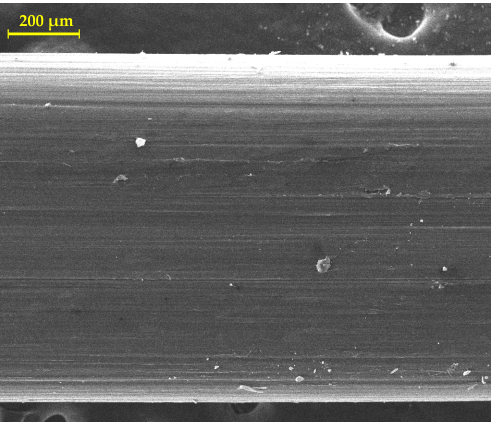

(d) PP

Figure 4. E-SEM magnification of fibers.

Further detailed views of AT and AT-S fibers are reported in Figure 5a,b, respectively. The distribution of the silica coating on the surface turns out to be uneven, fractured, and porous. The adhesion of the coating seems to be affected by the grooved morphology of the fibers, with the superficial wavy texture channelling the coating along the longitudinal wrinkles. This behavior is in perfect agreement with the observations by Signorini et al. [33], who investigated the effect of a similar rapid acid-catalysed silica coating on PP fibers. We remark that, because of both very smooth morphology of polyolefin surface and their chemically inert nature, an optimal adhesion of the coating would require quite long treatments, as pointed out by Di Maida et al. [39]. However, the choice of a rapid treatment represents a compromise between adequate effectiveness of the coating and its possible incorporation in industrial processing. The quality of the AT-S fibers-to-matrix adhesion is also clearly highlighted in Figure 6, which displays the AT-S fiber partially pulled out from the cement matrix in a failed specimen. Numerous bundles of hydration products of cement, with their peculiar acicular shape, remain firmly attached to the surface of fiber, even after pull-out (friction) occurrence. This bond is fostered by the presence of the thin silica hydrophilic coupling layer [33]. 


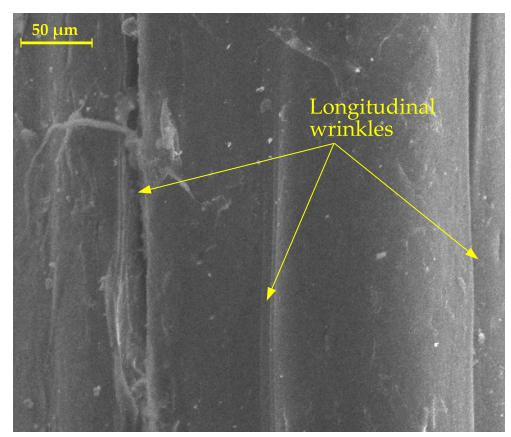

(a) AT

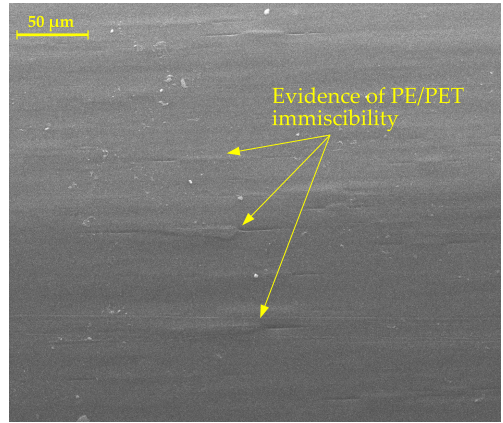

(c) RP

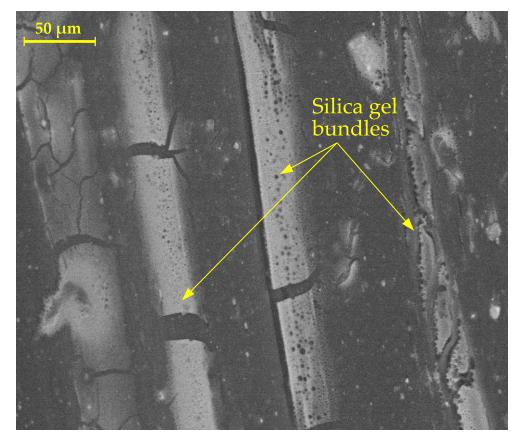

(b) AT-S

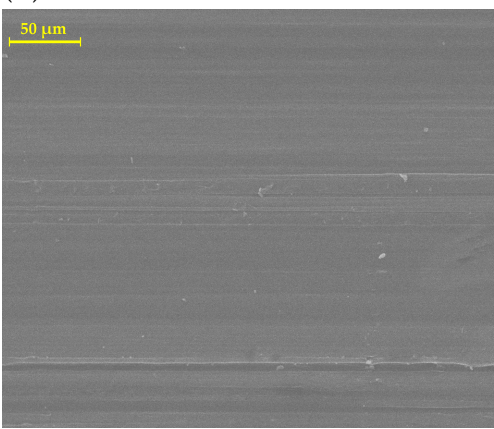

(d) PP

Figure 5. E-SEM high magnification fibers.

For the sake of completeness, in Figure 4c,d, we also report the detail of RP and PP fibers, respectively. As expected, such kinds of fibers present a very smooth surface, and only axial grooves are observed, as a direct consequence of the extrusion process. A higher magnification is also displayed in Figure $5 c, d$, the first showing the presence of some superficial asperities on RP surface, which may be ascribed to the immiscibility of PE and PET within the blend [48].
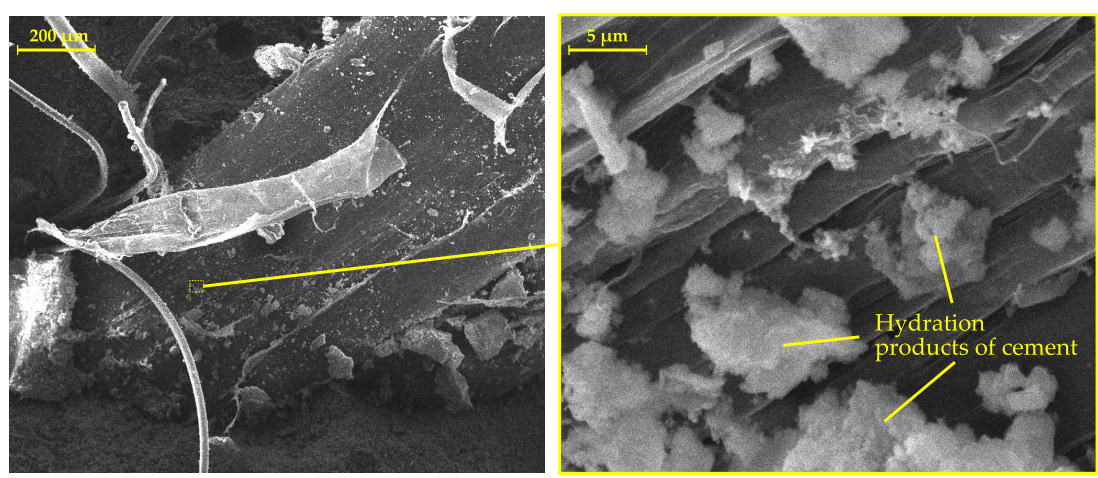

Figure 6. AT-S failed specimen: E-SEM at different levels of magnification.

\subsection{Mechanical Performance}

In this section, we critically discuss the flexural response of the four sets of FRCCs previously introduced. Specifically, we compare the performance of specimens including fully-recycled RP, AT, and AT-S fibers, in the light of those reinforced with virgin PP filaments.

We analyze the mean strength curves as a result of the displacement-controlled 3PB tests, here illustrated in Figure 7. The spotlight is first set on the initial behavior, up to the peak load, and second, but more fundamentally, on the post-peak behavior. The last, in fact, represents a crucial index, which gives an accurate insight into the FRCC mechanical performance and toughness. As far as the qualitative trend is considered, the response at the early stage of the test is mainly driven by the properties of the mortar, which plays 
the main role within the composite system. For this reason, the four FRCC sets exhibit a similar pseudo-linear trend, highlighted in the detail of Figure $7 \mathrm{~b}$. Conversely, the observed post-peak behavior largely varies, primarily depending on the shape of fibers, which turns out to be a crucial parameter in the design of highly-dissipative FRCC systems, as also pointed out in relevant contributions $[49,50]$. On the one hand, the inclusion of cylindrical draw-wire filaments (reference PP black dash-dotted line and RP violet dashed line) leads to a limited load drop immediately after first cracking, followed by a consistent monotonic softening branch (see [7,33]). Conversely, the presence of both AT (light-green solid line) and AT-S (dark-green solid line) fibers induces a more dramatic load drop, ascribable to the lower stiffness (i.e., smaller cross-section) of flattened fibers. However, AT and AT-S fibers produce a plastic and even plastic-hardening response, respectively, by maintaining a quite high residual load also for extreme applied deflection. This typical post-peak plateau reveals the good adhesion between fibers and matrix guaranteed by the particular flattened shape of the filaments [51], which introduce smaller discontinuities in the composite crosssection. As better clarified in the following, this good adhesion is further increased by the deposition of the silica coating on AT-S fibers, showing a better post-peak response.

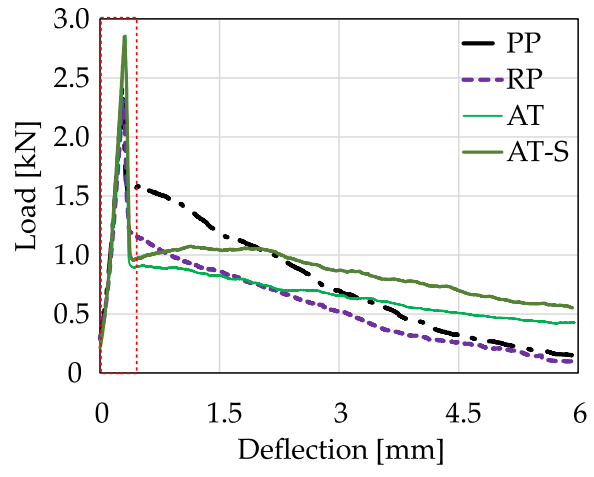

(a)

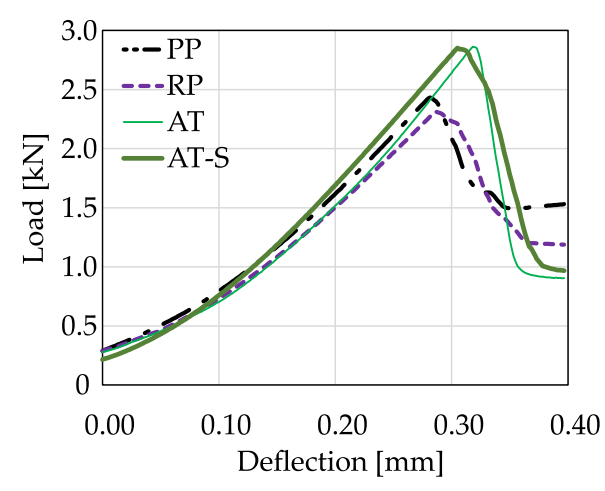

(b)

Figure 7. Strength curves (a); detail of the initial branch before cracking (b).

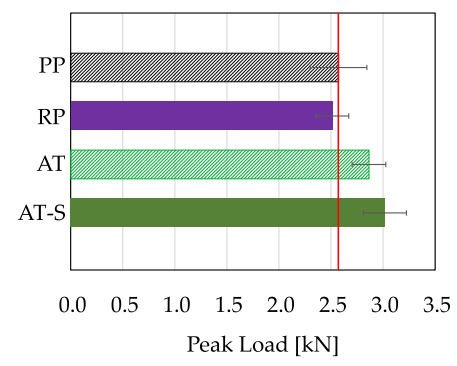

(a)

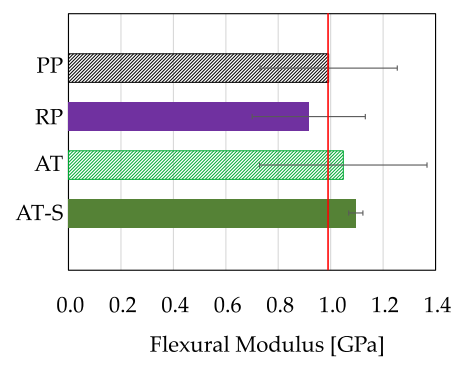

(b)

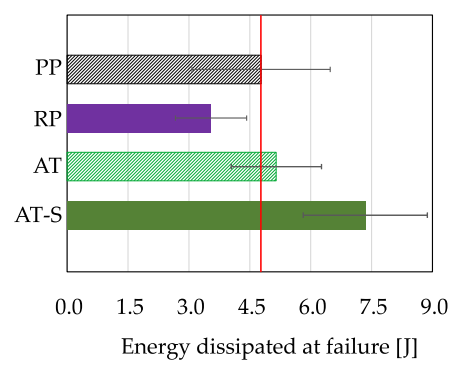

(c)

Figure 8. Bar-charts of: peak load (a); flexural modulus (b); dissipated energy (c), along with the standard deviation bands.

For a thorough discussion, in Figure 8, we compare the mechanical performance of the four FRCC sets also in terms of peak load (or peak stress), $F_{\mathrm{p}}$ (Figure 8a), elastic flexural modulus, $E_{\mathrm{f}}$ (Figure $8 \mathrm{~b}$ ), and energy dissipated at failure, $W$ (Figure $8 \mathrm{c}$ ). Standard deviation bands are also reported, shedding light on the statistical robustness of the illustrated experimental results.

Analysis of Figure 8a confirms once more the crucial role played by the shape of fibers in the crack formation process. Cylindrical PP and RP fibers attain approximately the same ultimate load, while flattened AT and AT-S filaments increase this reference value by $11.4 \%$ and $19.0 \%$, respectively. Therefore, flattened fibers permit to reach higher flexural strength, 
accordingly to the observations by Marthong [51], who employed hand-cut PET bottles as reinforcing platelets in concrete.

Table 4. Analysis of variance.

\begin{tabular}{cclcc}
\hline PI & Test & Groups & F & P [\%] \\
\hline \multirow{2}{*}{$E_{\mathrm{f}}$} & $i$ & all & 0.618 & 61.3 \\
& $i i$ & PP, RP, AT & 0.301 & 74.6 \\
\hline \multirow{2}{*}{$F_{\mathrm{P}}$} & $i i i$ & PP, RP, AT & 4.587 & 3.7 \\
& $i v$ & PP, RP, AT-S & 10.810 & 0.2 \\
\hline \multirow{2}{*}{$W$} & $v$ & PP, RP, AT & 2.967 & 9.0 \\
& $v i$ & PP, RP, AT-S & 8.721 & 0.6 \\
\hline
\end{tabular}

Besides, as expected, the stiffness of FRCC specimens at the uncracked stage, reported in Figure 8b, is only marginally affected by the different nature of the reinforcement. This observation is also confirmed by the results of a one-way analysis of variance (ANOVA), which assessed the statistical significance of the experimental data [52,53]. We carried out an evaluation of the combined trends of the Fisher-Snedecor ratio, F, and the probability, $P$. Through this analysis, which was performed on a specific performance index, PI, we could establish whether the sets of specimens investigated statistically belong to the same population (null hypothesis). Specifically, the more $F$ is greater than the unity, the more $P$ decreases, and the more the null hypothesis is unlikely to occur. Thus, if the variance within the sets is smaller than the one between them, the populations are mutually different from a statistical standpoint.

The results of six significant ANOVA tests are reported in Table 4. First, according to Analyses (i) and (ii), the flexural modulus turns out to be not reasonably affected by the properties of fibers, since $P$ attains $61.3 \%$ when all sets are considered, and even $74.6 \%$ discarding AT-S fibers, which show a notably narrower fluctuation. Conversely, the properties of both fibers and surface coating significantly influence the peak load and the dissipated energy, as illustrated by Analyses (iii)-(vi), which present a confidence level for the occurrence of the null hypothesis consistently lower than $10 \%$. In these analyses, we individually studied the reference PP/RP sets in combination with AT and AT-S groups, alternatively, with the aim of assessing the statistical robustness of the beneficial effects induced by the silica coating. Remarkably, the confidence level for the null hypothesis in PP/RP/AT-S groups drastically reduces with respect to the reference PP/RP/AT, thus proving that AT-S specimens most likely belong to a different population.

Accordingly to the previous observations, we also highlight that the sewing effect of the fibers gets in the game only once the tensile strength of the mortar is attained at the intrados of the specimen, with the main crack triggering at the mid-span. Typical bending cracked stage (Figure 9a) and failed specimen (Figure 9b) are illustrated in Figure 9, the latter making evident the bridging role of the fibrous reinforcement. Remarkably, this mechanism dramatically fosters the dissipation capability of the composite, which likely represents the most important performance index in the field of FRCCs and FRCs [54]. After the attainment of the flexural bearing capacity of the mortar (i.e., when the first cracking occurs), fiber-to-matrix interphase interactions start to drive the FRCC mechanical response [55].

As illustrated in the bar-chart of Figure 8c, the presence of flattened fibers may only slightly increase the energy dissipation capability of the composite, due to the dramatic amount of energy released at the first crack formation. Remarkably, the effect of the silica coating turns out to be crucial, deeply affecting the pull-out process in the cracked stage. Indeed, treated AT-S fibers lead to a notable increment on the dissipation capability, up to $42.6 \%$ and even $53.7 \%$, if compared to uncoated AT and virgin PP fibers, respectively.

Here, we focus our attention on fully-recycled PET/PE draw-wire fibers (RP). Analysis of Figures 7 and 8 highlights that the inclusion of the filaments at hand in the cement 
composite does not significantly affect the mechanical response, in terms of both peak load and post-peak softening branch, which are comparable to those of reference FRCC including virgin PP fibers. However, the low quality of RP blend causes a considerable energy release after first cracking, making the composite unable to recover a high level of residual bearing capacity during the pull-out stage. This behavior can be explained by taking into account the poor chemical affinity of the blend components. PE and PET, in fact, are immiscible [56], and the presence of internal shear stresses induces a mutual slip between the polymeric chains, leading to a decrease in the bearing capacity. This intrinsic characteristic of the blend and some possible solutions aimed at overcoming the issue were thoroughly investigated in a recent study by Yousfi et al. [48]. The scarce compatibility of PET and PE in the blend underlies also the slightly defective response in terms of dissipation capability. However, we remark that the loss in terms of energy dissipated at failure does not exceed the $25 \%$ with respect to virgin PP fibers (Figure 8c). A comprehensive analysis taking into strong account the remarkable environmental benefit linked to the re-use of end-life largely available low-grade PET/PE led us to state that, despite the observed decrease in the mechanical performance, RP fibers still represent a potential reinforcement for innovative FRCCs.

Table 5. Characteristic values and percentage variations with respect to reference set (PP) of the main PI.

\begin{tabular}{lcccccc}
\hline Set & $\boldsymbol{F}_{\mathrm{p}, \mathbf{k}}[\mathrm{kN}]$ & $\boldsymbol{\Delta}[\%]$ & $\boldsymbol{E}_{\mathrm{f}, \mathrm{k}}[\mathrm{GPa}]$ & $\boldsymbol{\Delta}[\%]$ & $\boldsymbol{W}_{\mathbf{k}}[\mathrm{J}]$ & $\boldsymbol{\Delta}[\%]$ \\
\hline PP & 2.08 & - & 0.52 & - & 1712 & - \\
\hline RP & 2.23 & +7.2 & 0.53 & +1.9 & 1891 & +10.5 \\
AT & 2.58 & +24.0 & 0.47 & -9.6 & 3150 & +84.0 \\
AT-S & 2.65 & +27.4 & 1.05 & +101.9 & 4592 & +168.2 \\
\hline
\end{tabular}

As previously pointed out, data scattering is a key parameter for design purposes. Therefore, we further assessed the statistical significance of the experimental data by evaluating the characteristic values of peak load, $F_{\mathrm{p}, \mathrm{k}}$, flexural modulus, $E_{\mathrm{f}, \mathrm{k}}$, and dissipated energy, $W_{\mathrm{k}}$, reported in Table 5, along with the percentage variation with respect to the reference FRCC including PP fibers, $\Delta$. Characteristic values for a generic PI $\left(A_{\mathrm{k}}\right)$ were evaluated by referring to the Eurocode "Basis of structural design" [57] [Equation D1], which provides the following prescription:

$$
A_{\mathrm{k}}=\mu(A)\left[1-k_{\mathrm{n}} \varsigma(A)\right],
$$

in which $\mu(A)$ and $\zeta(A)$ are the mean and the standard deviation values of the experimental quantity $A$, respectively, and the parameter $k_{\mathrm{n}}$ is the $5 \%$ percentile factor, which varies according to the number of test repetitions. In the case at hand, we tested at least five specimens for each set (see Table 3 ), thus adopting $k_{\mathrm{n}}=1.80$. On the one hand, specimens including flattened fibers reach higher values of $F_{\mathrm{p}, \mathrm{k}}$ and $W_{\mathrm{k}}$ with respect to the reference, in substantial agreement with the previous discussion on mean values (Figure 8a), owing to a comparable degree of data dispersion throughout the sets. On the other hand, $E_{\mathrm{f}, \mathrm{k}}$ of PP, RP, and AT composites remains comparable, while largely increases in the AT-S case. The motivation is twofold: (i) the effectiveness of the coating treatment, which generally improves the surface-to-matrix bond; and (ii) the beneficial effect of silica, which enhances the microstructure of the mortar by reducing the detrimental impact of local discontinuities within the matrix [58], thus leading to a narrow standard deviation (see Figure 8b). Therefore, although the mean flexural modulus of PP, RP, AT, and AT-S sets is approximately comparable, the tremendous repeatability of the results concerning AT-S specimens allows us to rely on an extremely higher design stiffness, if compared with all other FRCCs here investigated. 


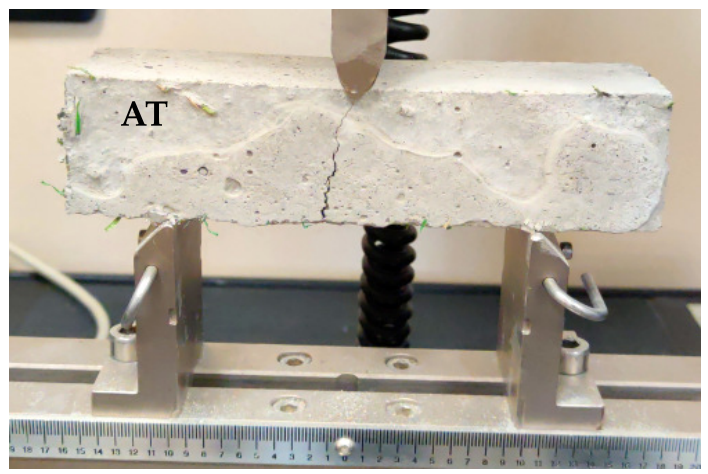

(a)

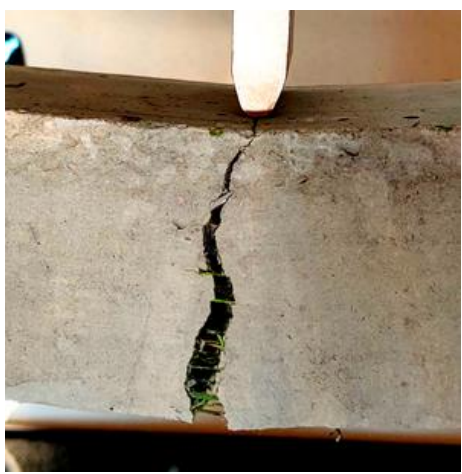

(b)

Figure 9. FRCC specimens during (a) and after testing (b).

\section{Conclusions}

In this paper, we assess the flexural response of Fiber Reinforced Cement Composites (FRCCs) including two kind of fully-recycled polymeric macrofibers. RP (Recycled Polymers) fibers consist of a blend of polyethylene terephthalate (PET) and polyethylene (PE) from low-grade food packaging, whereas AT (Artificial Turf) fibers are made of PE/polypropylene (PP) and are directly retrieved from sport facilities, without any further thermal treatment. This peculiar aspect is crucial in the perspective of reducing the environmental impact of cement composites. AT fibers are also treated with a rapid functionalization through silica deposition, with the aim of strengthening the interphase bond between the fibrous reinforcement and the surrounding mortar matrix. For the sake of clarity, the results are discussed in light of the reference performance of FRCCs including virgin PP fibers. The following conclusions can be drawn:

- $\quad$ The different properties (both compositional and physical) of the reinforcement fibers only marginally influence the first cracking strength of the composite, which is mainly governed by the characteristics of the cement mortar. However, the presence of flattened fully-recycled low-grade AT fibers even slightly benefits the mechanical response of the specimens, leading to a maximum load higher than the peak value attained by reference FRCC including virgin fibers only.

- The shape of fibers turns out to be a crucial parameter, which mainly steers the postpeak behavior of the specimen. Indeed, cylindrical draw-wired fibers induce a pure softening behavior (monotonically decreasing branch) in the cracked zone, i.e., after the maximum load is attained, whereas flattened fibers show a plastic (approximately constant branch) or even plastic-hardening (increasing branch) trend.

- Analysis of characteristic values of the main performance indices shows that the addition of flattened AT and cylindrical RP fibers may improve the mechanical response of the composite in terms of peak load and energy dissipated at failure, with respect to the reference specimens including virgin PP fibers.

- $\quad$ Silica coating deposited on AT fibers significantly fosters the interphase adhesion between reinforcement and cement matrix during the pull-out stage, leading to a hardening post-peak branch. Therefore, the surface treatment turns out to be a rapid, viable, and above all effective solution, largely improving the dissipation capability of FRCCs and imparting strongly hydrophilic attitudes to the fiber surface.

In conclusion, the present contribution shows how the inclusion of fully-recycled fibers as reinforcement in cement composites represents a first step to really promote the circular economy in the construction fields, finding possible application in cement composite systems as sustainable industrial pavements and fibrous shotcrete reinforcements for tunnels. Indeed, the balance between mechanical and environmental performance of FRCCs including recycled fibers may justify the replacement (partial or total) of virgin fibers and traditional rebar. 
Author Contributions: Conceptualization: C.S. and V.V.; Data curation: C.S.; Investigation: C.S. and V.V.; Methodology: C.S. and V.V.; Writing—original draft: C.S. and V.V.; Writing—review \& editing: C.S. and V.V. All authors have read and agreed to the published version of the manuscript.

Funding: This research was funded by Regione Emilia-Romagna grant POR-FESR "Progetto IMPReSA, Impiego di Materiali Plastici da Riciclo per malte e calcestruzzi Strutturali Alleggeriti" in the framework of strategic industrial research projects (POR-FESR 2014/2020-asse 1.2.2) [CUP E81F18000310009].

Institutional Review Board Statement: Not applicable.

Informed Consent Statement: Not applicable.

Data Availability Statement: Not applicable.

Acknowledgments: The contribution of Michele Tripoli and Gian Marco Macchioni in specimens manufacturing is gratefully acknowledged. The authors also thank Fabio Bergamini and Mauro Zapparoli for their valuable assistance during FT-IR and E-SEM analyses.

Conflicts of Interest: The authors declare no conflict of interest.

\section{References}

1. Di Prisco, M.; Lamperti, M.; Lapolla, S.; Khurana, R.S. HPFRCC thin plates for precast roofing. In Proceedings of the 2nd International Symposium on HPC, Kassel, Washington, DC, USA, 29 May-2 June 2008.

2. Vandewalle, L. Cracking behaviour of concrete beams reinforced with a combination of ordinary reinforcement and steel fibers. Mater. Struct. 2000, 33, 164-170. [CrossRef]

3. Di Prisco, M.; Colombo, M. FRC and HPFRC composites: From constitutive behaviour to structural applications. In Measuring, Monitoring and Modeling Concrete Properties; Springer: Berlin/Heidelberg, Germany, 2006; pp. 59-68.

4. Di Prisco, M.; Plizzari, G.; Vandewalle, L. Fibre reinforced concrete: New design perspectives. Mater. Struct. 2009, 42, 1261-1281. [CrossRef]

5. Nili, M.; Afroughsabet, V. The effects of silica fume and polypropylene fibers on the impact resistance and mechanical properties of concrete. Constr. Build. Mater. 2010, 24, 927-933. [CrossRef]

6. Lanzoni, L.; Nobili, A.; Tarantino, A.M. Performance evaluation of a polypropylene-based draw-wired fibre for concrete structures. Constr. Build. Mater. 2012, 28, 798-806. [CrossRef]

7. Di Maida, P.; Sciancalepore, C.; Radi, E.; Bondioli, F. Effects of nano-silica treatment on the flexural post cracking behaviour of polypropylene macro-synthetic fibre reinforced concrete. Mech. Res. Commun. 2018, 88, 12-18. [CrossRef]

8. Chunxiang, Q.; Patnaikuni, I. Properties of high-strength steel fiber-reinforced concrete beams in bending. Cem. Concr. Compos. 1999, 21, 73-81. [CrossRef]

9. Pilakoutas, K.; Neocleous, K.; Tlemat, H. Reuse of tyre steel fibres as concrete reinforcement. In Proceedings of the Institution of Civil Engineers-Engineering Sustainability; Thomas Telford Ltd.: London, UK, 2004; Volume 157, pp. 131-138.

10. Centonze, G.; Leone, M.; Aiello, M. Steel fibers from waste tires as reinforcement in concrete: A mechanical characterization. Constr. Build. Mater. 2012, 36, 46-57. [CrossRef]

11. Hu, H.; Papastergiou, P.; Angelakopoulos, H.; Guadagnini, M.; Pilakoutas, K. Mechanical properties of SFRC using blended manufactured and recycled tyre steel fibres. Constr. Build. Mater. 2018, 163, 376-389. [CrossRef]

12. Mastali, M.; Dalvand, A.; Sattarifard, A.; Illikainen, M. Development of eco-efficient and cost-effective reinforced self-consolidation concretes with hybrid industrial/recycled steel fibers. Constr. Build. Mater. 2018, 166, 214-226. [CrossRef]

13. Dong, X.; Ding, Y.; Wang, T. Spalling and mechanical properties of fiber reinforced high-performance concrete subjected to fire. J. Wuhan Univ. -Technol.-Mater. Sci. Ed. 2008, 23, 743-749. [CrossRef]

14. PlasticEurope. Plastics-the Facts: An Analysis of European Plastics Production, Demand and Waste Data. 2020. Available online: https: / / www.plasticseurope.org/en/resources/market-data (accessed on 15 December 2020).

15. Ochi, T.; Okubo, S.; Fukui, K. Development of recycled PET fiber and its application as concrete-reinforcing fiber. Cem. Concr. Compos. 2007, 29, 448-455. [CrossRef]

16. Fraternali, F.; Ciancia, V.; Chechile, R.; Rizzano, G.; Feo, L.; Incarnato, L. Experimental study of the thermo-mechanical properties of recycled PET fiber-reinforced concrete. Compos. Struct. 2011, 93, 2368-2374. [CrossRef]

17. Marthong, C.; Sarma, D.K. Influence of PET fiber geometry on the mechanical properties of concrete: An experimental investigation. Eur. J. Environ. Civ. Eng. 2016, 20, 771-784. [CrossRef]

18. Foti, D. Preliminary analysis of concrete reinforced with waste bottles PET fibers. Constr. Build. Mater. 2011, 25, 1906-1915. [CrossRef]

19. Foti, D. Use of recycled waste pet bottles fibers for the reinforcement of concrete. Compos. Struct. 2013, 96, 396-404. [CrossRef]

20. Pelisser, F.; Montedo, O.R.K.; Gleize, P.J.P.; Roman, H.R. Mechanical properties of recycled PET fibers in concrete. Mater. Res. 2012, 15, 679-686. [CrossRef] 
21. Won, J.P.; Jang, C.I.; Lee, S.W.; Lee, S.J.; Kim, H.Y. Long-term performance of recycled PET fibre-reinforced cement composites. Constr. Build. Mater. 2010, 24, 660-665. [CrossRef]

22. Luyt, A.S. Polyolefin blends. In Polyolefin Compounds and Materials; Springer: Berlin/Heidelberg, Germany, 2016 ; pp. 107-156.

23. Cifuentes, H.; García, F.; Maeso, O.; Medina, F. Influence of the properties of polypropylene fibres on the fracture behaviour of low-, normal-and high-strength FRC. Constr. Build. Mater. 2013, 45, 130-137. [CrossRef]

24. Caggiano, A.; Gambarelli, S.; Martinelli, E.; Nisticò, N.; Pepe, M. Experimental characterization of the post-cracking response in hybrid steel/polypropylene fiber-reinforced concrete. Constr. Build. Mater. 2016, 125, 1035-1043. [CrossRef]

25. Sakthivel, P.; Govindasami, S.; Suman, N. Flexural performance of hybrid polypropylene-polyolefin FRC composites. Asian J. Civ. Eng. 2019, 20, 515-526. [CrossRef]

26. Signorini, C.; Marinelli, S.; Volpini, V.; Nobili, A.; Radi, E. Recycling synthetic fibres from sport facilities for the Fibre Reinforced Concrete (FRC) technology. Submitted for publication to Journal of Building Engineering, 2020

27. Novák, I.; Pollak, V.; Chodak, I. Study of surface properties of polyolefins modified by corona discharge plasma. Plasma Process. Polym. 2006, 3, 355-364. [CrossRef]

28. Shukla, S.; Harad, A.M.; Jawale, L.S. Chemical recycling of PET waste into hydrophobic textile dyestuffs. Polym. Degrad. Stab. 2009, 94, 604-609. [CrossRef]

29. Paosawatyanyong, B.; Kamlangkla, K.; Hodak, S. Hydrophobic and hydrophilic surface nano-modification of PET fabric by plasma process. J. Nanosci. Nanotechnol. 2010, 10, 7050-7054. [CrossRef] [PubMed]

30. Ahsani, M.; Yegani, R. Study on the fouling behavior of silica nanocomposite modified polypropylene membrane in purification of collagen protein. Chem. Eng. Res. Des. 2015, 102, 261-273. [CrossRef]

31. Felekoglu, B.; Tosun, K.; Baradan, B. A comparative study on the flexural performance of plasma treated polypropylene fiber reinforced cementitious composites. J. Mater. Process. Technol. 2009, 209, 5133-5144. [CrossRef]

32. Signorini, C.; Sola, A.; Nobili, A.; Siligardi, C. Lime-cement textile reinforced mortar (TRM) with modified interphase. J. Appl. Biomater. Funct. Mater. 2019, 17, 2280800019827823. [CrossRef]

33. Signorini, C.; Sola, A.; Malchiodi, B.; Nobili, A.; Gatto, A. Failure mechanism of silica coated polypropylene fibres for Fibre Reinforced Concrete (FRC). Constr. Build. Mater. 2020, 236, 117549. [CrossRef]

34. Tu, L.; Kruger, D.; Wagener, J.; Carstens, P. Surface modified polypropylene fibres for use in concrete. Mag. Concr. Res. 1998, 50, 209-217. [CrossRef]

35. Lovata, N.L.; Fahmy, M. Interfacial bond study of a chemically treated polypropylene fibre-reinforced concrete. Constr. Build. Mater. 1987, 1, 83-87. [CrossRef]

36. Denes, F.S.; Feldman, D.; Hua, Z.; Zheng, Z.; Young, R.A. Cementitious-matrix composites from SiCl4-plasma-activated polypropylene fibres. J. Adhes. Sci. Technol. 1996, 10, 61-77. [CrossRef]

37. Hench, L.L.; West, J.K. The sol-gel process. Chem. Rev. 1990, 90, 33-72. [CrossRef]

38. Brinker, C.J.; Scherer, G.W. Sol-Gel Science: The Physics and Chemistry of Sol-Gel Processing; Academic Press: Cambridge, MA, USA, 2013.

39. Di Maida, P.; Radi, E.; Sciancalepore, C.; Bondioli, F. Pullout behavior of polypropylene macro-synthetic fibers treated with nano-silica. Constr. Build. Mater. 2015, 82, 39-44. [CrossRef]

40. Sika Italia S.p.A. Sika MonoTop X2 ${ }^{\odot}$, 2020. Available online: https://ita.sika.com/content/dam/dms/itgen/5/sika_monotop_x2 f.pdf (accessed on 14 January 2021).

41. UNI EN 1015-11. Determinazione Della Resistenza A Flessione E A Compressione Della Malta Indurita; Technical Report; British Standards Institution-BSI and CEN European Committee for Standardization: London, UK, 2007.

42. UNI EN 1015-11. Methods of Test for Mortar For Masonry-Part 11: Determination Of Flexural and Compressive Strength of Hardened Mortar; Technical Report; British Standards Institution-BSI and CEN European Committee for Standardization: London, UK, 2007.

43. Signorini, C.; Nobili, A.; Sola, A.; Messori, M. Designing epoxy viscosity for optimal mechanical performance of coated Glass Textile Reinforced Mortar (GTRM) composites. Constr. Build. Mater. 2020, 233, 117325. [CrossRef]

44. Wong, A.Y.; Lam, F. Study of selected thermal characteristics of polypropylene/polyethylene binary blends using DSC and TGA. Polym. Test. 2002, 21, 691-696. [CrossRef]

45. Feifel, S.; Lisdat, F. Silica nanoparticles for the layer-by-layer assembly of fully electro-active cytochrome c multilayers. J. Nanobiotechnol. 2011, 9, 59. [CrossRef] [PubMed]

46. Irzh, A.; Ghindes, L.; Gedanken, A. Rapid deposition of transparent super-hydrophobic layers on various surfaces using microwave plasma. ACS Appl. Mater. Interfaces 2011, 3, 4566-4572. [CrossRef] [PubMed]

47. Faghihzadeh, F.; Anaya, N.M.; Schifman, L.A.; Oyanedel-Craver, V. Fourier transform infrared spectroscopy to assess molecularlevel changes in microorganisms exposed to nanoparticles. Nanotechnol. Environ. Eng. 2016, 1, 1. [CrossRef]

48. Yousfi, M.; Soulestin, J.; Vergnes, B.; Lacrampe, M.F.; Krawczak, P. Compatibilization of Immiscible Polymer Blends by Organoclay: Effect of Nanofiller or Organo-Modifier? Macromol. Mater. Eng. 2013, 298, 757-770. [CrossRef]

49. Xu, Z.; Hao, H.; Li, H. Experimental study of dynamic compressive properties of fibre reinforced concrete material with different fibres. Mater. Des. 2012, 33, 42-55. [CrossRef]

50. Meza, A.; Siddique, S. Effect of aspect ratio and dosage on the flexural response of FRC with recycled fiber. Constr. Build. Mater. 2019, 213, 286-291. [CrossRef] 
51. Marthong, C. Effects of PET fiber arrangement and dimensions on mechanical properties of concrete. Ies J. Part Civ. Struct. Eng. 2015, 8, 111-120. [CrossRef]

52. Nobili, A. Durability assessment of impregnated Glass Fabric Reinforced Cementitious Matrix (GFRCM) composites in the alkaline and saline environments. Constr. Build. Mater. 2016, 105, 465-471. [CrossRef]

53. Nobili, A.; Signorini, C. On the effect of curing time and environmental exposure on impregnated Carbon Fabric Reinforced Cementitious Matrix (CFRCM) composite with design considerations. Compos. Part Eng. 2017, 112, 300-313. [CrossRef]

54. Tschegg, E.K.; Schneemayer, A.; Merta, I.; Rieder, K.A. Energy dissipation capacity of fibre reinforced concrete under biaxial tension-compression load. Part I: Test equipment and work of fracture. Cem. Concr. Compos. 2015, 62, 195-203. [CrossRef]

55. Radi, E.; Lanzoni, L.; Sorzia, A. Analytical modelling of the pullout behavior of synthetic fibres treated with nano-silica. Procedia Eng. 2015, 109, 525-532. [CrossRef]

56. Fenouillot, F.; Cassagnau, P.; Majesté, J.C. Uneven distribution of nanoparticles in immiscible fluids: Morphology development in polymer blends. Polymer 2009, 50, 1333-1350. [CrossRef]

57. UNI EN 1990. Eurocode: Basis of Structural Design; Technical Report; Comité Européen de Normalisation (CEN): Brussels, Belgium, 2002.

58. Singh, L.P.; Goel, A.; Bhattachharyya, S.K.; Ahalawat, S.; Sharma, U.; Mishra, G. Effect of morphology and dispersibility of silica nanoparticles on the mechanical behaviour of cement mortar. Int. J. Concr. Struct. Mater. 2015, 9, 207-217. [CrossRef] 